\title{
Biological Activity of Optically Active Salithion and Salioxon
}

\author{
Akinori Hirashima, Isaac ISHAAYA, * Ryohei UENo, \\ Yoshifumi ICHIYAMA, ** Shao-Yong W U*** \\ and Morifusa ETO \\ Department of Agricultural Chemistry, Kyushu University, \\ Fukuoka 812, Japan
}

Received September 6, 1988

\begin{abstract}
Salioxon enantiomers were obtained from salithion enantiomers by MCPBA oxidation. The larvicidal and adulticidal activities of salithion enantiomers, and the anti-cholinesterase activity of salioxon enantiomers were determined on house flies. On Iarvae, the potency of $(S)(-)$-salithion $\left(L C_{50}=1.1 \mathrm{ppm}\right)$ was about two-fold higher than the $(R)(+)$-enantiomer $\left(\mathrm{LC}_{50}=2.1 \mathrm{ppm}\right)$. A similar ratio was obtained when these compounds were applied topically to female adults. The relative potency of these enantiomers correlated well with the anti-cholinesterase activity of their respective oxidative enantiomers, $(R)(+)$-and $(S)(-)$-salioxon, which are assumed to have been formed after their application to the insects.
\end{abstract}

Salithion (2-methoxy-4H-1,3,2-benzodioxaphosphorin 2-sulfide) ${ }^{1)}$ has been developed as an insecticide by modifying the structure of the six-membered cyclic metabolite (M-1) formed from tri-o-tolyl phosphate (TOCP). In order to study the relationship between the absolute configuration and the insecticidal activity of salithion, syntheses of optically active salithions were carried out by a two-step phophorylating method. ${ }^{2)}$ However, their optical purities were only about $80 \%{ }^{3}$ ) Therefore, optically pure ( $>98 \%$ e.e.) salithions were synthesized by the proline method and their absolute configurations were determined. $^{4)}$

Salithion itself is not a potent acetylcholinesterase inhibitor, but its biologically oxidized form salioxon (2-methoxy-4H-1,3,2-benzodioxaphosphorin 2-oxide) ${ }^{5}$ ) has shown strong inhibitory activity.

The biological activity of salithion and salioxon enantiomers has not been studied yet in detail. This paper describes the insecticidal activity of salithion enantiomers and the antiacetylcholinesterase activity of their respective oxidative salioxon enantiomers, which are assumed to be formed in vivo.

\section{Materials and Methods}

Thin-layer silica gel plates (60F-254, Merck), $5 \times 2 \mathrm{~cm}$ and $5 \mathrm{~mm}$ thick, were used for analysis, and $20 \times 20 \mathrm{~cm}$ and $0.5,1.0$ or $2.0 \mathrm{~mm}$ thick for preparative thin-layer chromatography (TLC). ${ }^{1} \mathrm{H}-\mathrm{NMR}$ was measured with a JEOL JNM-FX 100 spectrometer at $100 \mathrm{MHz}$. Tetramethylsilane (TMS) was used as an internal standard, and chemical shift values are expressed in $\delta\left(\mathrm{CDCl}_{3}\right)$ ppm. Optical rotations were measured with a Hitachi-Union Giken PM101 polarimeter and are expressed as specific rotations.

Synthesis of 2-methoxy-4H-1,3,2-benzodioxaphosphorin 2-oxide (salioxon).

a) From salithion. An ice-cooled solution of salithion $(140 \mathrm{mg})$, prepared by the proline method, ${ }^{4)}$ in $8 \mathrm{ml}$ of benzene was mixed with an ice-cooled solution of $210 \mathrm{mg}$ of $m$-chloroperbenzoic acid (MCPBA) in $5 \mathrm{ml}$ of benzene. The mixture was stirred at $5 \sim 10^{\circ} \mathrm{C}$ for $3 \mathrm{hr}$, and then at room temperature for $1 \mathrm{hr}$. After filtration and concentration, the salioxon was purified by TLC with a

Present address:

* Department of Entomology, Agricultural Research Organization, The Volcani Center, Bet Dagan 50-250, Israel.

** Hisamitsu Pharmaceutical K. K., Tokyo, Japan.

*** Institute of Applied Chemistry, Beijing Agricultural University, Beijing, China. 
mixture of hexane-ethyl acetate $(1: 1.2)$ as the developing solvent, yielding about $60 \mathrm{mg}(30 \%)$. From the $(+)$ - and $(-)$-salithion enantiomers, $(-)$ - and $(+)$-salioxon enantiomers were obtained, respectively, the $[\alpha]_{D}$ being $-5.0^{\circ}$ $\left(1.73, \mathrm{CHCl}_{3}\right)$ and $+4.0^{\circ}\left(1.93, \mathrm{CHCl}_{3}\right)$.

b) From a diastereomeric mixture of (S)-2-[1-(2-methoxycarbonylpyrrolidyl)]-4H-1,3,2-benzodioxaphosporin 2-sulfide $(P S)$. To a solution of $\mathrm{PS}^{4)}(200 \mathrm{mg})$ in $10 \mathrm{ml}$ of methylene chloride, MCPBA (210 mg) in $5 \mathrm{ml}$ of methylene chloride was added at $0^{\circ} \mathrm{C}$. The mixture was stirred at room temperature for $3 \mathrm{hr}$, then refluxed for $6 \mathrm{hr}$ and washed with an aqueous solution of sodium bicarbonate. The organic layer was dried, concentrated, and then purified by TLC with a mixture of hexane ethyl acetate (1:1.4) as a developing solvent. This procedure gave $50 \mathrm{mg}(26 \%)$ of $(S)$-2-[1-(2-methoxycarbonylpyrrolidyl)]4H-1,3,2-benzodioxaphosphorin 2-oxide. ${ }^{1} \mathrm{H}$-NMR: $1.8 \sim 2.4\left(4 \mathrm{H}, \mathrm{m}, \mathrm{NCCH}_{2} \mathrm{CH}_{2} \mathrm{C}\right), 3.27\left(2 \mathrm{H}, 2 \mathrm{t}, \mathrm{NCH}_{2}\right)$, $3.69\left(3 \mathrm{H}, \mathrm{s}, \mathrm{CH}_{3}\right), 4.20 \sim 4.44(1 \mathrm{H}, \mathrm{m}, \mathrm{NCH}), 4.84 \sim 5.64$ $\left(2 \mathrm{H}, \mathrm{m}, \mathrm{CH}_{2} \mathrm{O}\right), 6.8 \sim 7.4(4 \mathrm{H}, \mathrm{m}$, aromatic). This compound was subjected to methanolysis in a methanol $(20 \mathrm{ml})$ solution containing $2 \mathrm{~g}$ of conc. sulfuric acid. After stirring at room temperature for $12 \mathrm{hr}$, the methanol was evaporated. The residue was neutralized, extracted with methylene chloride, and dried. The concentrated material was further purified by TLC as already mentioned, yielding $8 \mathrm{mg}(24 \%)$ of the desired product.

${ }^{1} \mathrm{H}-\mathrm{NMR}$ features of the a) and b) salioxon preparations were identical with those shown by the authentic sample. ${ }^{5}$

\section{Bioassay.}

a) Feeding method. The dietary effect of the test compounds on larval and pupal mortality was measured according to the previously published method. ${ }^{6)}$ A house fly diet $(10 \mathrm{~g}$, Oriental Kobo K. K., Tokyo, Japan) was mixed with $30 \mathrm{ml}$ of an acetone solution of the test compound, or with $30 \mathrm{ml}$ of an acetone alone as a control. After the solvent had been evaporated under a hood for 2 days at room temperature, $12 \mathrm{~g}$ of water was added to the diet and the whole mixed well. The diet was distributed in $2 \mathrm{~g}$ portions in $13 \times 150 \mathrm{~mm}$ test tubes. Three larvae of susceptible (SRS) house fly, $1 \sim 2$ days after hatching and weighing $2 \pm 1 \mathrm{mg}$ each, were introduced to each test tube along with a thin piece of cotton placed over the diet to permit pupation. The tubes were kept at $28^{\circ} \mathrm{C}$ until pupation and adult emergence were complete.

b) Topical Application Method. A test sample in $1 \mu \mathrm{l}$ of acetone was topically applied to susceptible (SRS) and fenitrothion resistant $\left(3-Y_{\mathrm{F}}\right)$ female house flies, Musca domestica, the mortality being measured after $24 \mathrm{hr}$. The resistant strain $3-\left(\mathrm{Y}_{\mathrm{F}}\right)$ was obtained by rearing the 3rd Yumenoshima strain (3-Y) under fenitrothion pressure for ten successive generations.

c) Acetylcholinesterase Inhibition Assay. Susceptible (SRS) house fly AChE was prepared by homogenizing 10 fly heads $/ \mathrm{ml}$ of phosphate buffer $(0.1 \mathrm{M}, \mathrm{PH} 8.0)$ and centrifuging for $10 \mathrm{~min}$ at $2,500 \times g$ and $10,000 \times g$, respectively. Assays with $0.25 \mathrm{ml}$ of the supernatant diluted to $2.5 \mathrm{ml}$ with the buffer and various concentrations of the test compound in $50 \mu \mathrm{l}$ of acetone were run by incubating for $15 \mathrm{~min}$ at $25^{\circ} \mathrm{C}$. Aliquots of $1 \mathrm{ml}$ were tested for residual $\mathrm{AChE}$ activity according to the Ellman procedure. $^{7)}$

\section{Results and Discussion}

\section{Synthesis}

Salioxon could be obtained from the proline derivative (PS) by the two different routes shown in Fig. 1. Both routes consist of oxidative desulfurization and methanolysis, but the

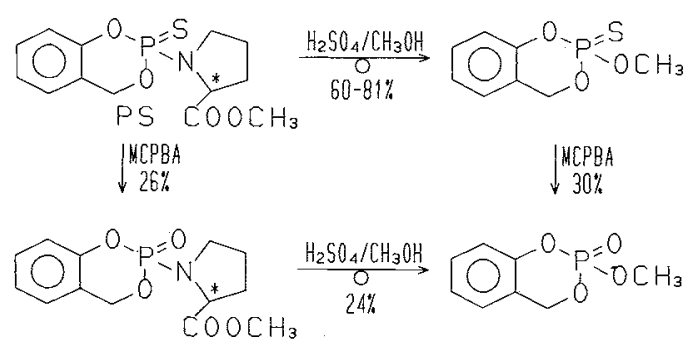

Fig. 1. Synthetic Routes for Salioxon.

Table I. Effect of Dietary Salithion Enantiomers on Susceptible (SRS) House Fly Pupation and EMERgence

\begin{tabular}{ccc}
\hline & \multicolumn{2}{c}{ Relative to control $(\%)^{a}$} \\
\cline { 2 - 3 } dietary conc. (ppm) & Pupation & Emergence \\
\hline$(S)(-)$-salithion & & \\
0.75 & $96 \pm 10^{b}$ & $105 \pm 11^{b}$ \\
1.0 & $65 \pm 14^{c}$ & $47 \pm 18^{c d}$ \\
1.5 & $12 \pm 6^{e}$ & $5 \pm 5^{e}$ \\
2.0 & $0^{e}$ & $0^{e}$ \\
$(R)(+)-$ salithion & & \\
1.0 & $93 \pm 7^{b}$ & $105 \pm 11^{b}$ \\
1.5 & $66 \pm 6^{c}$ & $63 \pm 10^{c}$ \\
2.0 & $65 \pm 12^{c}$ & $78 \pm 14^{b c}$ \\
2.5 & $35 \pm 9^{d}$ & $36 \pm 11^{d}$ \\
3.0 & $4 \pm 4^{e}$ & $0^{e}$ \\
\hline
\end{tabular}

a Data are the average of 10 replicates of 3 larvae each. Larvae of $1 \sim 2$ days old $(2 \pm 1 \mathrm{mg})$ were introduced into the diet and kept until adult emergence was complete. The average pupation and emergence of the untreated control was $86 \pm 7$ and $63 \pm 9 \%$, respectively.

$b, c, d, e$ Represent data which differ significantly from each other at $p=0.05$ within the same column. 
reaction order occurs in a reversed way. These conversions were found to be feasible by using a diastereomeric mixture of PS and racemic salithion. Such oxidative desulfurization and acidic methanolysis have been proved by several researchers in other organophosphorus compounds to proceed stereoselectively..$^{8 \sim 11)}$ In fact, we found that a salithion analog (6chloro-2-methoxy-4-methyl-1,3,2-benzodioxaphosphorin 2-sulfide) was stereospecifically converted to the corresponding salioxon ana$\log$ by MCPBA oxidation with retention of the configuration at the phosphorus atom. ${ }^{12)}$ The $(-)$ - and $(+)$-salioxons were derived from $(R)(+)$ - and $(S)(-)$-salithions by MCPBA oxidation, respectively. The absolute configurations of the $(-)$ - and $(+)$-salioxons were assigned as $(S)$ and $(R)$, respectively, based on the configuration of the starting salithion and the reaction mechanism.

\section{Biological activity}

The $(S)(-)$ - and $(R)(+)$-salithion enantiomers applied to the diet showed strong larvicidal activity resulting in $100 \%$ mortality at 2 and $3 \mathrm{ppm}$, respectively (Table I), and strong insecticidal activity against susceptible (SRS) house fly adults when applied topically (Table III). The $\mathrm{LC}_{50}$ values of dietary salithion carried out with larvae and the $\mathrm{LD}_{50}$ values for topical application carried out with adults revealed that $(S)(-)$-salithion was about twofold more potent than the $(R)(+)$-enantiomer (Tables II and III). In a previous paper, ${ }^{12)}$ we found that $(S)(-)$-salithion $(84 \%$ e.e. $)$ and $(R)(+)$-salithion $(79 \%$ e.e. $)$ obtained by the

Table II. LC 50 Values of Dietary Salithion Enantiomers for Cumulative Mortality Obtained until Pupation or Emergence

\begin{tabular}{clc}
\hline Enantiomer & $\begin{array}{c}\text { Cumulative } \\
\text { mortality }^{a}\end{array}$ & $\begin{array}{c}\mathrm{LC}_{50}, \mathrm{ppm} \\
(95 \% \text { confidence limits })\end{array}$ \\
\hline \multirow{2}{*}{$(S)(-)$} & Until pupation & $1.1(1.0 \sim 1.2)$ \\
& Until emergence & $1.0(0.9 \sim 1.1)$ \\
$(R)(+)$ & Until pupation & $2.1(1.8 \sim 2.5)$ \\
& Until emergence & $2.4(2.0 \sim 2.9)$ \\
\hline
\end{tabular}

a See Table I for the procedure and assay. two-step phosphorylating method ${ }^{2)}$ resulted in $\mathrm{LD}_{50}$ values of 0.05 and $0.07 \mu \mathrm{g} / \mathrm{fly}$, respectively. Hence, the difference in $\mathrm{LD}_{50}$ values of the enantiomers was more obvious when optically purer samples were used (Table III).

As in the case of the five-membered cyclic organophosphorus compounds, 4-isopropyl2-methoxy-1,3,2-oxazaphospholidine 2-sulfide $\left({ }^{\text {iPMOS }}\right)^{13)}$ and 2-methoxy-5-phenyl-1,3,2-oxazaphospholidine 2 -sulfide (5-PMOS) ${ }^{14)}$ the resistant ratios $(R / S)$ of the enantiomers were fairly close and much lower than those of the commercial acyclic organophosphorus insecticides, fenitrothion (dimethyl 3-methyl-4nitrophenyl phosphorothionate) and malathion [S-1,2-bis(ethoxycarbonyl)ethyl dimethyl phosphorothiolothionate], indicating their possible use for controlling house flies resistant to the latter compounds (Table III).

Salithion $(0.085 \mu \mathrm{g})$ showed a $50 \%$ inhi-

Table III. LD $_{50}$ Values of Salithion Enantiomers ApPlied Topically to Susceptible (SRS) AND Resistant $\left(3-Y_{F}\right.$ ) House Fly Adults

\begin{tabular}{cccc}
\hline \multirow{2}{*}{ Compound } & \multicolumn{2}{c}{$\mathrm{LD}_{50}, \mu \mathrm{g} / \mathrm{fly}(95 \%$ confidence limits $)$} \\
\cline { 2 - 4 } & $\mathrm{SRS}(S)$ & $3-\mathrm{Y}_{\mathrm{F}}(R)$ & $R / S$ ratio \\
\hline$(S)(-)$-Salithion & 0.05 & 0.40 & 8.0 \\
$98 \%$ e.e. & $(0.03 \sim 0.06)$ & $(0.32 \sim 0.56)$ & \\
$(R)(+)$-Salithion & 0.12 & 0.91 & 7.6 \\
$99 \%$ e.e. & $(0.10 \sim 0.16)$ & $(0.83 \sim 1.05)$ & \\
Fenitrothion & 0.073 & $>200$ & $>2740$ \\
& $(0.063 \sim 0.084)$ & & \\
Malathion & 0.67 & $>200$ & $>299$ \\
& $(0.57 \sim 0.80)$ & & \\
\hline
\end{tabular}

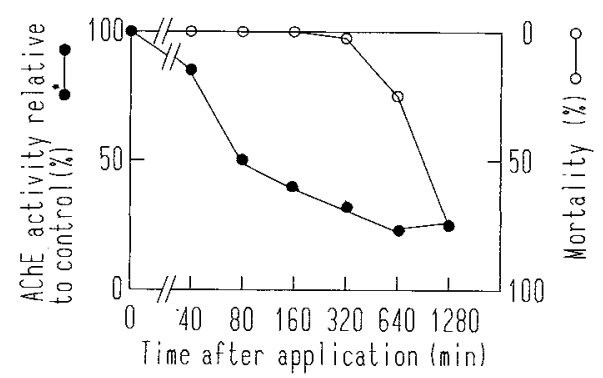

Fig. 2. Effect of Salithion Applied Topically to Susceptible (SRS) House Flies at the $\mathrm{LD}_{\text {so }}$ Value $(0.085 \mu \mathrm{g} / \mathrm{fl})$ on the Mortality and $\mathrm{AChE}$ Activity at Various Periods after Application. 
bition of acetylcholinesterase in the susceptible (SRS) house flies at $80 \mathrm{~min}$ after topical application, while a $50 \%$ mortality occurred only after about $20 \mathrm{hr}$ (Fig. 2). $(R)(+)$-Salioxon, obtained by MCPBA oxidation from $(S)(-)$ salithion, showed stronger anti-cholinesterase activity $\left(I_{50}=0.170 \mu \mathrm{M}\right)$ than $(S)(-)$-salioxon $\left(I_{50}=0.534 \mu \mathrm{M}\right)$ against the susceptible (SRS) house fly head enzyme. These results agree with the concept that the high toxicity of $(S)(-)$-salithion to both house fly larvae and adults results from its biological conversion to $(R)(+)$-salioxon, exhibiting higher inhibitory activity on acetylcholinesterase.

Acknowledgments. This work was supported in part by a Grant-in-Aid for Scientific Research from the Ministry of Education, Science and Culture of Japan. We thank Kazuhiko Oyama and Ryuko Takeya in this laboratory for their skillful technical assistance.

\section{References}

1) M. Eto, Rev. Plant Protec. Res., 9, 1 (1976).

2) A. Hirashima and M. Eto, Agric. Biol. Chem., 47, 2831 (1983).

3) S.-Y. Wu, A. Hirashima, E. Kuwano and M. Eto, Agric. Biol. Chem, 51, 537 (1987).

4) S.-Y. Wu, A. Hirashima, M. Eto, K. Yanagi, E. Nishioka and K. Moriguchi, Agric. Biol. Chem., 53, 157 (1989).

5) M. Eto, Y. Kinoshita, T. Kato and Y. Oshima, Agric. Biol. Chem., 27, 789 (1963).

6) I. Ishaaya and J. E. Casida, Pestic. Biochem. Physiol., 4, 484 (1974).

7) G. L. Ellman, K. D. Countney, V. Andres and R. M. Featherstone, Biochem. Pharmacol., 7, 88 (1961).

8) A. W. Herriott, J. Am. Chem. Soc., 93, 3304 (1971).

9) D. B. Cooper, C. R. Hall, J. M. Marrison and T. D. Inch, J. Chem. Soc., Perkin I, 1977, 1969.

10) P. W. Lee, L. Allahyari and T. R. Fukuto, Biochem. Pharmacol., 25, 2671 (1976)

11) H. Ohkawa, N. Mikami and J. Miyamoto, Agric. Biol. Chem., 40, 2125 (1976).

12) S.-Y. Wu and M. Eto, J. Pesticide Sci., 12, 95 (1987).

13) S.-Y. Wu, R. Takeya, M. Eto and C. Tomizawa, $J$. Pesticide Sci., 12, 221 (1987).

14) S.-Y. Wu, A. Hirashima, R. Takeya and M. Eto, Agric. Biol. Chem., 52, 2911 (1988). 